\title{
Energy drinks: pros and cons
}

\begin{abstract}
Energy drinks (EDs) constitute a health hazard among adolescents and young adults. Few beneficial effects of EDs are reported as they are frequently consumed by youth to overcome fatigue and sleepiness. EDs may also promote healing of soft tissue wounds. They are ingested alone or mixed with alcohol to lessen alcohol sedation. They may cause cardiovascular manifestations like tachycardia, elevated blood pressure, arrhythmias, electrocardiographic changes and myocardial ischemia. On the nervous system, EDs affect cognition, mental health and motor skills, and they may increase the risk adventures. Prenatal consumption of EDs results in increased locomotion, anxiety and irritability of the newly born infants. Moreover, excessive ingestion of these drinks is associated with blood changes, renal and gastrointestinal disorders, obesity and dental caries. It is recommended that regulatory sales restrictions, particularly toward young adults, must be undertaken to minimize the magnitude of this health problem.
\end{abstract}

Keywords: energy drinks, cardiovascular, nervous, digestive, renal, dental, breast feeding, obesity
Volume 6 Issue 2 - 2019

\section{Heshmat SW Haroun \\ Department of Anatomy, Cairo University, Egypt}

Correspondence: Heshmat SW Haroun, Professor of Anatomy and Embryology, Anatomy Department, Kasr AI Ainy Faculty of Medicine, Cairo University, Egypt,

Email heshmatsabet@gmail.com,

heshmat.haroun@kasralainy.edu.eg.com

Received: January 29, 2019 | Published: March 25, 2019
Abbreviations: BP, blood pressure; ED, energy drink; GABA, gamma-amino butyric acid; G-6-PDH, glucose-6-phosphate dehydrogenase; GPA, grade point average; HR, heart rate; LQTS, long QT syndrome

\section{Introduction}

Energy drinks (EDs) are beverages which contain sugar, caffeine, taurine, herbs and vitamins. They have been increasingly consumed, particularly by teen agers and young adults, in the States, Europe and Asia. Marketing of the beneficial effects of EDs magnifies their role in improving physical and mental status. These beverages are thought to overcome sleepiness, maintain alertness, and increase physical and mental fitness. Recently, consumers use the stimulant effect of EDs to counteract the sedative effect of alcohol. EDs are more used by male athletes practicing sports, by students during study and exams, and by young adults facing career interviews. The current article aims at reviewing the hazards of excessive consumption of EDs.

A controversy has developed regarding the benefits and possible adverse effects of EDs. Most of the benefits of EDs are related to two constituents: caffeine and taurine. High caffeine level, of ED, may result in caffeine intoxication in susceptible individuals. Caffeine intoxication may result in tachycardia, cardiac arrhythmias, vomiting, fits and death. Also, excessive consumption of EDs may be associated with poor mental health, metabolic and renal disorders, and obesity. Frequent ED consumers usually suffer from headache, anger, breathlessness, polyurea, and seizures. Dental enamel erosion could be produced by the acidity of these drinks. EDs mixed with alcohol are linked to increased risk-taking behaviors by adolescents. ${ }^{2-6}$

Justifications for consumption of EDs, among adolescents of both genders and different ethnicities, were assessed as follows: to promote energy (61\%), to accentuate study concentration (32\%), to potentiate sports performance $(29 \%)$, and to diminish weight $(9 \%)$. Many users mix ED with alcohol or illicit drugs such as marijuana, cocaine, and methamphetamine. ${ }^{7,8}$ Red Bull, as one of EDs, was supposed to accentuate the volume of concomitantly consumed alcohol. ${ }^{9}$ Consumption of alcohol mixed with EDs, by adolescents, has the risk of practicing gambling. ${ }^{10}$ In a group of Saudi female university students, the reasons to consume EDs included having good company with friends, better learning concentration, and successful exam performance. The commonest side effect of ED, among these users, was headache and the rarest one was allergy. Many users were aware of the adverse effects of ED consumption during pregnancy and lactation. ${ }^{11}$ Regular check-up of the stimulant effect of EDs on the cardiovascular and nervous systems is required in young athletes to guard against health hazards. ${ }^{12}$ It is also advisable to launch restrictions on EDs marketing to youth below the age of 18 years. ${ }^{13}$

\section{EDs and the cardiovascular system}

The commonest detrimental effects of EDs are imposed on the cardiovascular and nervous systems. ${ }^{3,14}$ Recent studies have attributed the cardiovascular hazards of EDs mainly to caffeine and sugar. ${ }^{15}$ Serious cardiovascular effects of EDs include cardiac arrhythmias, myocardial infarction, prolonged QT interval, aortic dissection, and death. ${ }^{16-18}$ There is a good evidence that caffeine moderately increases the blood pressure (BP) and heart rate (HR). ${ }^{19}$

EDs were found to produce changes in the autonomic cardiovascular functions: Valsalva ratio, systolic and diastolic BP, mean arterial BP, and pulse pressure. These changes sometimes necessitated hospitalization and were enhanced by overweight or obesity. ${ }^{20,21}$ EDs alter electrolytes and result in repolarization abnormalities leading to arrhythmias and sudden death. Two cases of fatal ventricular arrhythmias were recently reported in young individuals following ED consumption. ${ }^{22,23}$ On the contrary, a previous research documented that acute ingestion of Red Bull ED, by healthy young volunteers, had increased both systolic and diastolic BP as well as HR without changing the ventricular repolarization. ${ }^{24}$

Excessive ingestion of EDs is reported to significantly increase the QTc interval by $6 \mathrm{~ms}$ and the systolic blood pressure by $4 \mathrm{mmHg} .{ }^{25}$ On the contrary, other reports reveal that consumption of EDs by healthy young adults had non-significant changes in systolic and diastolic BP, PR and QTc intervals, and QRS duration. ${ }^{26}$ In patients with familial long QT syndrome (LQTS), caffeinated EDs induced an acute increase in the arterial $\mathrm{BP} .{ }^{27}$ Other researchers mentioned that EDs consumption did not change QTc interval, HR and systolic BP whereas the diastolic BP and mean BP were slightly elevated. ${ }^{28}$

Few documents support a possible link between excessive consumption of caffeinated EDs and incidence of myocardial infarction. ${ }^{29-32}$ In-vitro, the caffeine content of ED exerted a 
significant inotropic action on human myocardial specimens while taurine content did not. ${ }^{33}$ In male Wistar rats, long-term consumption of EDs had significantly increased the cardiac glucose and glycogen levels, the total protein level as well as the ALT and AST enzymes; meanwhile, the total cholesterol level was significantly decreased. ${ }^{34}$ Some authors postulate that ED consumption increases platelet aggregation, thus accentuating the risk of blood hypercoagulability and thrombus formation. ${ }^{35}$

\section{EDs and the cognitive, mental and motor functions}

Caffeinated EDs are assumed to increase mental and physical energy, however these effects are of short term. These drinks proved to have a negative impact on mental health in young consumers. ${ }^{36}$ Excessive consumption of EDs was associated with a lower grade point average (GPA) among undergraduates.$^{37}$ Among UK secondary school students, consumption of EDs was linked to poor academic results for maths and English; an observation which was thought not to be due to ED but to lacking breakfast or having junk food. ${ }^{38}$ Some university students considered EDs as a tool to manage health, performance and appearance. ${ }^{39}$ Following consumption of EDs, Italian young athletes showed a minimal anxiety but no depression. ${ }^{40}$

Caffeine, in EDs, is supposed to change the brain chemistry through increasing the activities of the enzymes: cytochrome $\mathrm{C}$ oxidase and glucose-6-phosphate dehydrogenase (G-6-PDH), and the neurotransmitters: gamma-amino butyric acid (GABA) and dopamine. ${ }^{12}$ The detrimental effects of EDs in Korean youth were assessed to include sleep deprivation, severe stress, depression, and suicide planning and attempts; such effects were more evident in those habitually consuming junk foods.$^{41}$ In medical students, ED consumption was associated with insomnia and irritability. ${ }^{42}$ Also, ingestion of $3 \mathrm{mg} / \mathrm{kg}$ of caffeine, in an $\mathrm{ED}$, was found to increase insomnia and nervousness without gender differences. ${ }^{43}$ Chronic sleep deprivation and circadian rhythm disruption, caused by highly caffeinated EDs, may increase risk-adventures and use of illicit drugs. ${ }^{44-47}$ Furthermore, consumption of EDs at the age of 14 years is considered as a predictor of drug use at the age of $16 .^{48}$

Taurine amino acid is richly present in the brain, retina, heart, reproductive organs, meat and seafood. ${ }^{49}$ It is sometimes hypothesized that neither caffeine nor glucose has a significant effect on cognition, mood and self-judgement. ${ }^{50}$ In male Wistar rats a mixture of caffeine and taurine, but not full ED, could improve memory and attention. ${ }^{51}$ A young male experienced a fit which was linked to excessive consumption of ED rich in caffeine and taurine ${ }^{52}$ Also, a psychotic episode, probably caused by excessive ED, was reported in a young adult lacking history of psychotic ailments. ${ }^{53}$

Ingestion of sugar-free EDs had led to decreased intracortical facilitation, shortened simple reaction time, and increased pre- and post-exercise facilitations of motor potentials. ${ }^{54}$ Shortly after ingestion of two cans of Red Bull, a middle-aged male showed abnormal treadmill test compared to normal test before ED ingestion. ${ }^{55}$ Improvement of physical performance in muscle strength, endurance exercise tests, and sports is correlated to the dose of taurine in EDs. ${ }^{56}$ However, caffeine and taurine administration at doses like those of EDs did not promote sprint cycling performance..$^{57}$

ED consumption negatively impacts the executive functions of adolescents. ${ }^{58}$ Among university students of both sexes, ED shots were significantly associated with poorly scored hand steadiness tests, but reaction time tests were satisfactory. ${ }^{59} \mathrm{ED}$ shots also significantly impaired pistol aiming steadiness. ${ }^{60}$ Deployed soldiers in Afghanistan consumed greater amounts of caffeine and EDs to combat the drawbacks of sleep loss on cognition and operational performance. ${ }^{61}$ In healthy college students of both sexes, ED shot enhanced smaller muscle group performance (like isolated forehand stroke), but not larger muscle group performance (like countermovement vertical jump). ${ }^{62}$ Only few studies demonstrated an ergogenic effect of EDs on muscle strength and power. ${ }^{63}$

It is postulated that EDs might correct some adverse effects of alcohol alone like cognition defects, headache, fatiguability, dry mouth, and motor deficits. ${ }^{64}$ However, in Taiwan male volunteers, drinks with high caffeine: alcohol ratio did not correct the defective motor function caused by alcohol alone. ${ }^{65}$ In male Swiss mice, ED mixed with alcohol significantly reduced motor skills. ${ }^{66}$ In rat brain and liver, EDs alone or mixed with alcohol significantly altered malondialdehyde (as a lipid peroxidation marker), and superoxide dismutase, catalase and glutathione peroxidase (as oxidative stress markers).$^{67}$

\section{EDs and other body organs}

The deleterious effects of Power Horse, as one of the commercial EDs, were investigated on the structure of the pancreas and gastric fundic mucosa of albino rat. In this experiment, the serum levels of insulin and glucose were significantly elevated whereas the serum level of gastrin was significantly diminished. Structurally, the pancreas showed features of excessive stimulation of $\beta$-cells whereas the gastric fundic mucosa exhibited reduced number of parietal cells. ${ }^{68}$ Clinical manifestations of acute hepatitis, in a middle-aged male, were linked to daily ingestion of 4-5 EDs for three weeks. ${ }^{69}$

It is also common that some breast-feeding women tend to ingest EDs and excess vitamins to combat fatigue and sleepiness. Some infants display irritability and sleep disturbances following exposure to excessive caffeine in breast milk and/or excessive prenatal vitamins. ${ }^{70}$ Mice, born to mothers consuming EDs during pregnancy and lactation, had shown increased locomotion and anxiety. Also, there were several histological changes like fatty degeneration of hepatocytes, degeneration of renal glomeruli with dilated urinary spaces, pyknosis and chromatolysis of cerebral and medullary neurons, and alterations in the cerebellar Purkinje cells. ${ }^{71}$ In addition, acute renal failure is rarely encountered on excessive consumption of EDs alone without mixing with alcohol. ${ }^{72}$ Despite its diuretic effect, caffeine content of EDs, is documented to slightly increase the occurrence of renal stones. ${ }^{73}$

Hematological hazards of EDs were sometimes discovered. On exposure to Red Bull and Power Horse, male Wistar albino rats demonstrated significant reduction in red blood cell, platelet and neutrophil counts, in haemoglobin content and haematocrit value. Occasionally, ultrastructural nuclear and cytoplasmic alterations were observed in peripheral blood cells in all rats exposed to all types of EDs. ${ }^{74}$ Furthermore, an association was determined between daily consumption of acidic EDs and dental enamel erosion. ${ }^{75}$ In rats, a beneficial effect of EDs was also observed in the form of enhancement of soft tissue wound healing possibly through increased collagen deposition, re-epithelialization and new vascularization in the wound. ${ }^{76}$ Furthermore, excessive ingestion of sugar- sweetened drinks during the second trimester of pregnancy was linked to greater incidence of obesity in mid-childhood. ${ }^{77}$ 


\section{Conclusion}

Consumption of energy drinks (EDs) has some benefits as they combat fatigue and sleepiness and increase endurance and fitness. However, many health hazards are shown to be associated with excessive consumption of these drinks by youth. There is a growing evidence of their negative impact on the cardiovascular and nervous systems. Also, these beverages may affect other body organs like pancreas, stomach, kidney, breast and teeth. Adolescents and young adults must be screened and closely monitored for EDs use and their health consequences. Healthcare providers should inform adolescents and their families about the risks of excessive consumption of caffeinated drinks. Regulatory sales restrictions must be undertaken to minimize the magnitude of this health problem.

\section{Acknowledgments}

None.

\section{Conflicts of interest}

The authors declare there is no conflicts of interest.

\section{References}

1. Sankararaman S, Syed W, Medici V, et al. Impact of energy drinks on health and well-being. Curr Nutr Rep. 2018;7(3):121-130.

2. De Sanctis V, Soliman N, Soliman AT, et al. Caffeinated energy drink consumption among adolescents and potential health consequences associated with their use: a significant public health hazard. Acta Biomed. 2017;88(2):222-231.

3. Ali F, Rehman H, Babayan Z, et al. Energy drinks and their adverse health effects: A systematic review of the current evidence. Postgrad Med. 2015;127(3):308-322.

4. Wassef B, Kohansieh M, Makaryus AN. Effects of energy drinks on the cardiovascular system. World J Cardiol. 2017;9(11):796-806.

5. Al-Shaar L, Vercammen K, Lu C, et al. Health effects and public health concerns of energy drink consumption in the united states: a minireview. Front Public Health. 2017;5:225

6. Bashir D, Reed-Schrader E, Olympia RP, et al. Clinical symptoms and adverse effects associated with energy drink consumption in adolescents. Pediatr Emerg Care. 2016;32(11):751-755.

7. Nordt SP, Claudius I, Rangan C, et al. Reasons for energy drink use and reported adverse effects among adolescent emergency department patients. Pediatr Emerg Care. 2017;33(12):770-773.

8. Martins A, Ferreira C, Sousa D, et al. Consumption patterns of energy drinks in Portuguese adolescents from a city in northern Portugal. Acta Med Port. 2018;31(4):207-212.

9. Roldán M, Echeverry-Alzate V, Bühler KM, et al. Red Bull® energy drink increases consumption of higher concentrations of alcohol. Addict Biol. 2017

10. Vieno A, Canale N, Potente R, et al. The multiplicative effect of combining alcohol with energy drinks on adolescent gambling. Addict Behav. 2018;82:7-13.

11. Rahamathulla MP. Prevalence, side effects and awareness about energy drinks among the female university students in Saudi Arabia. Pak $J$ Med Sci. 2017;33(2):347-352.

12. Petrelli F, Grappasonni I, Evangelista D, et al. Mental and physical effects of energy drinks consumption in an Italian young people group: a pilot study. J Prev Med Hyg. 2018;59(1):E80-E87.
13. Harris JL, Munsell CR. Energy drinks and adolescents: what's the harm? Nutr Rev. 2015;73(4):247-257.

14. García A, Romero C, Arroyave C, et al. Acute effects of energy drinks in medical students. Eur J Nutr. 2017;56(6):2081-2091.

15. Grasser EK, Miles-Chan JL, Charrière N, et al. Energy drinks and their impact on the cardiovascular system: potential mechanisms. Adv Nutr. 2016;7(5):950-960.

16. Mangi MA, Rehman H, Rafique M, et al. Energy drinks and the risk of cardiovascular disease: a review of current literature. Cureus. 2017;9(6):e1322.

17. Mattioli AV, Pennella S, Manenti A, et al. Energy drink overconsumption can trigger atrial fibrillation. $J$ Cardiovasc Med (Hagerstown). 2016;17(12):902-904.

18. Sattari M, Sattari A, Kazory A. Energy drink consumption and cardiac complications: a case for caution. J Addict Med. 2016;10(4):280-282.

19. Peveler WW, Sanders GJ, Marczinski CA, et al. Effects of energy drinks on economy and cardiovascular measures. $J$ Strength Cond Res. 31(4):882-887.

20. Majeed F, Yar T, Alsunni A, et al. Synergistic effect of energy drinks and overweight/obesity on cardiac autonomic testing using the Valsalva maneuver in university students. Ann Saudi Med. 2017;37(3):181-188.

21. Shah SA, Chu BW, Lacey CS, et al. Impact of acute energy drink consumption on blood pressure parameters: a meta-analysis. Ann Pharmacother. 2016;50(10):808-815.

22. Kozik TM, Shah S, Bhattacharyya M, et al. Cardiovascular responses to energy drinks in a healthy population: The C-energy study. Am J Emerg Med. 2016;34(7):1205-1209.

23. Enriquez A, Frankel DS. Arrhythmogenic effects of energy drinks. $J$ Cardiovasc Electrophysiol. 2017;28(6):711-717.

24. Elitok A, Öz F, Panc C, et al. Acute effects of Red Bull energy drink on ventricular repolarization in healthy young volunteers: a prospective study. Anatol J Cardiol. 2015;15(11):919-922.

25. Shah SA, Occiano A, Nguyen TA, et al. Electrocardiographic and blood pressure effects of energy drinks and Panax ginseng in healthy volunteers: A randomized clinical trial. Int J Cardiol. 2016;218:318323.

26. Hajsadeghi S, Mohammadpour F, Manteghi MJ, et al. Effects of energy drinks on blood pressure, heart rate, and electrocardiographic parameters: An experimental study on healthy young adults. Anatol $J$ Cardiol. 2016;16(2):94-99.

27. Gray B, Ingles J, Medi C, et al. Cardiovascular effects of energy drinks in familial long QT syndrome: a randomized cross-over study. Int $J$ Cardiol. 2017;231:150-154.

28. Brothers RM, Christmas KM, Patik JC, et al. Heart rate, blood pressure and repolarization effects of an energy drink as compared to coffee. Clin Physiol Funct Imaging. 2017;37(6):675-681.

29. Samanta D. Reversible cerebral vasoconstriction syndrome: another health hazard of energy drinks? Clin Pediatr (Phila). 2015;54(2):186187.

30. Monnard CR, Montani JP, Grasser EK. Cerebro- and cardio-vascular responses to energy drink in young adults: is there a gender effect? Front Physiol. 2016;7:346.

31. Lippi G, Cervellin G, Sanchis-Gomar F. Energy drinks and myocardial ischemia: a review of case reports. Cardiovasc Toxicol. 2016;16(3):207-212.

32. Wajih Ullah M, Lakhani S, Siddiq W, et al. Energy drinks and myocardial infarction. Cureus. 2018;10(5):e2658. 
33. Chaban R, Kornberger A, Branski N, et al. In-vitro examination of the positive inotropic effect of caffeine and taurine, the two most frequent active ingredients of energy drinks. BMC Cardiovasc Disord. 2017;17(1):220

34. Munteanu C, Rosioru C, Tarba C, et al. Long-term consumption of energy drinks induces biochemical and ultrastructural alterations in the heart muscle. Anatol J Cardiol. 2018;19(5):326-323.

35. Pommerening MJ, Cardenas JC, Radwan ZA, et al. Hypercoagulability after energy drink consumption. J Surg Res. 2015;199(2):635-640.

36. Richards G, Smith AP. A review of energy drinks and mental health, with a focus on stress, anxiety, and depression. J Caffeine Res. 2016;6(2):49-63.

37. Champlin SE, Pasch KE, Perry CL. Is the consumption of energy drinks associated with academic achievement among college students? J Prim Prev. 2016;37(4):345-359.

38. Smith AP, Richards G. Energy drinks, caffeine, junk food, breakfast, depression and academic attainment of secondary school students. $J$ Psychopharmacol. 2018;32(8):893-899.

39. Thorlton J, Collins WB. Underlying beliefs associated with college student consumption of energy beverages. West J Nurs Res. 2018;40(1):5-19.

40. Owolabi JO, Olatunji SY, Olanrewaju AJ. Caffeine and cannabis effects on ital neurotransmitters and enzymes in the brain tissue of juvenile experimental rats. Ann Neurosci. 2017;24(2):65-73

41. Park S, Lee Y, Lee JH. Association between energy drink intake, sleep, stress, and suicidality in Korean adolescents: energy drink use in isolation or in combination with junk food consumption. Nutr $J$ 2016;15(1):87.

42. Casuccio A, Bonanno V, Catalano R, et al. Knowledge, attitudes, and practices on energy drink consumption and side effects in a cohort of medical students. J Addict Dis. 2015;34(4):274-283.

43. Salinero JJ, Lara B, Abian-Vicen J, et al. The use of energy drinks in sport: perceived ergogenicity and side effects in male and female athletes. Br J Nutr. 2014;112(9):1494-1502.

44. Logan RW, Hasler BP, Forbes EE, et al. Impact of sleep and circadian rhythms on addiction vulnerability in adolescents. Biol Psychiatry. 2018;83(12):987-996

45. Koivusilta L, Kuoppamäki H, Rimpelä A. Energy drink consumption, health complaints and late bedtime among young adolescents. Int $J$ Public Health. 2016;61(3):299-306.

46. Kelly CK, Prichard JR. Demographics, health, and risk behaviors of young adults who drink energy drinks and coffee beverages. J Caffeine Res. 2016;6(2):73-81.

47. Holubcikova J, Kolarcik P, Madarasova Geckova A, et al. Regula energy drink consumption is associated with the risk of health and behavioural problems in adolescents. Eur J Pediatr. 2017;176(5):599605 .

48. Barrense-Dias Y, Berchtold A, Akre C, et al. Consuming energy drinks at the age of 14 predicted legal and illegal substance use at 16. Acta Paediatr. 2016;105(11):1361-1368.

49. Caine JJ, Geracioti TD. Taurine, energy drinks, and neuroendocrine effects. Cleve Clin J Med. 2016;83(12):895-904.

50. Ullrich S, de Vries YC, Kühn S, et al. Feeling smart: effects of caffeine and glucose on cognition, mood and self-judgment. Physiol Behav. 2015;151:629-637.

51. Valle MTC, Couto-Pereira NS, Lampert C, et al. Energy drinks and their component modulate attention, memory, and antioxidant defences in rats. Eur J Nutr. 2018;57(7):2501-2511.
52. Matuszkiewicz E, Łukasik-Głębocka M, Sommerfeld K, et al. Energy drinks as a cause of seizures--real or possible danger? Case report. Przegl Lek. 2015;72(1):42-44.

53. Hernandez-Huerta D, Martin-Larregola M, Gomez-Arnau J, et al. Psychopathology related to energy drinks: a psychosis case report. Case Rep Psychiatry. 2017:5094608.

54. Concerto C, Infortuna C, Chusid E, et al. Caffeinated energy drink intake modulates motor circuits at rest, before and after a movement Physiol Behav. 2017;179:361-368.

55. Choudhury TR, Abdool MA, Galasko G. Energy drinks give you wings but also an abnormal exercise test. BMJ Case Rep. 2017.

56. Souza DB, Del Coso J, Casonatto J, et al. Acute effects of caffeinecontaining energy drinks on physical performance: a systematic review and meta-analysis. Eur J Nutr. 2017;56(1):13-27.

57. Jeffries O, Hill J, Patterson SD, et al. Energy drink doses of caffeine and taurine have a null or negative effect on sprint performance. $J$ Strength Cond Res. 2017.

58. Dawodu A, Cleaver K. Behavioural correlates of energy drink consumption among adolescents: A review of the literature. $J$ Child Health Care. 2017;21(4):446-462.

59. Jacobson BH, Hughes PP, Conchola EC, et al. Effect of energy drinks on selected fine motor tasks. Percept Mot Skills. 2015;121(1):170-178.

60. Monaghan TP, Jacobson BH, Sellers JH, et al. Effects of energy beverage consumption on pistol aiming steadiness in law enforcement officers. J Strength Cond Res. 2017;31(9):2557-2561.

61. McLellan TM, Riviere LA, Williams KW, et al. Caffeine and energy drink use by combat arms soldiers in Afghanistan as a countermeasure for sleep loss and high operational demands. Nutr Neurosci. 2018;11:110 .

62. Jacobson BH, Hester GM, Palmer TB, et al. Effect of energy drink consumption on power and velocity of selected sport performance activities. J Strength Cond Res. 2018;32(6):1613-1618.

63. Mora-Rodriguez R, Pallarés JG. Performance outcomes and unwanted side effects associated with energy drinks. Nutr Rev. 2014;72 Suppl $1: 108-120$

64. Lalanne L, Lutz PE, Paille F. Acute impact of caffeinated alcoholic beverages on cognition: A systematic review. Prog Neuropsychopharmacol Biol Psychiatry. 2017;76:188-194.

65. Cheng WJ, Lin CC, Cheng Y, et al. Effects of caffeinated alcoholic beverages with low alcohol and high caffeine content on cognitive and motor functions. Hum Psychopharmacol. 2017;32(6).

66. Asorey LG, Carbone S, Gonzalez BJ, et al. Behavioral effects of the combined use of alcohol and energy drinks on alcohol hangover in an experimental mice model. Neurosci Lett. 2018;670:1-7.

67. Reis R, Charehsaz M, Sipahi H, et al. Energy drink induced lipid peroxidation and oxidative damage in rat liver and brain when used alone or combined with alcohol. J Food Sci. 2017;82(4):1037-1043.

68. Ayuob N, El Beshbeishy R. Impact of an energy drink on the structure of stomach and pancreas of albino rat: can omega-3 provide a protection? PLoS One. 2016;11(2):e0149191.

69. Harb JN, Taylor ZA, Khullar V, et al. Rare cause of acute hepatitis: a common energy drink. BMJ Case Rep. 2016.

70. Thorlton J, Ahmed A, Colby DA. Energy drinks: implications for the breastfeeding mother. MCN Am J Matern Child Nurs. 2016;41(3):179_ 185 
71. Al-Basher GI, Aljabal H, Almeer RS, et al. Perinatal exposure to energy drink induces oxidative damage in the liver, kidney and brain, and behavioral alterations in mice offspring. Biomed Pharmacother. 2018;102:798-811

72. Greene E, Oman K, Lefler M. Energy drink-induced acute kidney injury. Ann Pharmacother. 2014;48(10):1366-1370.

73. Peerapen $\mathrm{P}$, Thongboonkerd V. Caffeine in kidney stone disease: risk or benefit? Adv Nutr. 2018;9(4):419-424.

74. Khayyat LI, Essawy AE, Al Rawy MM, et al. Comparative study on the effect of energy drinks on haematopoietic system in Wistar albino rats. J Environ Biol. 2014;35(5):883-891.
75. Søvik JB, Skudutyte-Rysstad R, Tveit AB, et al. Sour sweets and acidic beverage consumption are risk indicators for dental erosion. Caries Res. 2015;49(3):243-250.

76. Tek M, Toptas O, Akkas I, et al. Effects of energy drinks on soft tissue healing. J Craniofac Surg. 2014;25(6):2084-2088.

77. Gillman MW, Rifas-Shiman SL, Fernandez-Barres S, et al. Beverage intake during pregnancy and childhood adiposity. Pediatrics. $2017 ; 140(2)$. 